Palestra

O Simpósio

Internacional de

Paisagismo

\title{
O espírito da paisagem
}

\author{
CARLOS FERNANDO DE MOURA DELPHIM ${ }^{(1)}$
}

\begin{abstract}
RESUMO
Desde a antiguidade, a humanidade acredita que os sítios e paisagens, além de suas características físicas, seriam animados por presenças imateriais, o espírito dos lugares. A moderna preservação do patrimônio cultural reconhece a necessidade de se preservar, junto com os bens imateriais, essas entidades.
\end{abstract}

Palavras-chave: Espírito dos lugares, patrimônio cultural, sítios, paisagens.

\begin{abstract}
O ESPÍRITO DA PAISAGEM
"My books are always about living in places, not just rushing through them. As we get to know Europe slowly, tasting the wines, cheeses, and characters of different countries you begin to realize that the important determinant of any culture is after all - the spirit of place. Just as one particular vineyard will always give you a special wine with discernible characteristics so a Spain, an Italy, a Greece will always give you the same type of culture--will express itself through the human beings just as it does through its wild flowers"
\end{abstract}

Lawrence Durrell, Landscape and Character

Em todas as culturas e civilizações, o modelo ideal e mais perfeito de paisagem para o ser humano são os jardins do Paraíso. O Éden de nossa tradição judaico-cristã não era apenas um lugar, era também um estado. Assim são as paisagens que nos emocionam: não são apenas lugares, são fontes de inspiração de diferentes estados de espírito, indestacáveis de seus aspectos materiais. As paisagens podem ser animadas por toda sorte de entidades imateriais, desde os seres mais simplórios aos estados mais elevados e inefáveis que a alma humana pode atingir.

As pessoas mais simples acreditam que certos lugares são habitados por criaturas fantásticas que lhes despertam sentimentos de medo ou respeito. Fantasmas, assombrações, fadas, bruxas, anões, gênios, elfos, gnomos, sílfides, nereidas, salamandras, cada um desses seres escolhe um tipo de paisagem ou um local onde ocorra predominância de um dos quatro elementos, água, ar, terra ou fogo, para aí se instalar.
Já os homens de espírito mais elevado apreendem o que as paisagens têm de mais sutil, captando o que elas têm de mais sublime, considerando-as locais de manifestação divina que lhes desperta estados de adoração.

A recente edição de mais uma declaração sobre bens de valor patrimonial pelo International Council on Sites and Monuments - ICOMOS, a Carta do Espirito dos Lugares, foi recebida por aqueles que se dedicam à preservação de bens culturais como uma grande e bem-vinda inovação. Na verdade, nada há de novidade nesse conceito a não ser o fato de se tentar aplicá-lo na preservação do patrimônio cultural. O espírito dos lugares sempre desempenhou um papel decisivo na vida dos indivíduos e dos povos desde a antiguidade. Lugares e paisagens apresentam aspectos especiais e mesmo essenciais ao ser humano. Não apenas as pessoas, mas também grupos sociais inteiros sentem-se atraídos por características particulares de certos sítios e ambientes naturais, podendo ocorrer que alguns cheguem a despertar sentimentos de tal dimensão, que acabem por se tornar sagrados.

A atual declaração do ICOMOS é parte de um conjunto de medidas tomadas pelos órgãos patrimoniais com vistas à proteção e promoção do espírito dos lugares que constitui a essência de vida, social e espiritual de monumentos, sítios e paisagens. Para sua preservação e utilização foram considerados valores intangíveis como memória, crenças, conhecimento tradicional, formas de ligação ao lugar e as comunidades locais guardiãs destes valores em consenso com a Convenção do Patrimônio Mundial de 1972. Já em 2005, a Declaração Xi'an do ICOMOS chamara atenção para a conservação de aspectos físicos, visuais e naturais

(1) Arquiteto, IPHAN - Instituto do Patrimônio Histórico Artístico Nacional, Brasília-DF. carlos.delphim@iphan.gov.br 
como práticas sociais e espirituais, costumes, conhecimento tradicional e outras formas e expressões intangíveis na proteção e promoção dos monumentos, sítios e paisagens que compõem o patrimônio mundial.

Outras Cartas do ICOMOS reconhecem também a importância das dimensões intangíveis do patrimônio e o valor espiritual dos lugares. Em decorrência da natureza indivisível do patrimônio tangível e intangível e aos significados, valores e contexto que o patrimônio intangível assegura aos objetos e lugares. Atualmente o ICOMOS está considerando a adoção de uma nova Carta e desenvolvendo novos conceitos e um novo vocabulário especificamente voltados para a dimensão intangível e os mecanismos culturais e sociais intrínsecos dos monumentos, sítios e paisagens.

O espírito do lugar é constituído por elementos tangíveis como edificações, sítios, paisagens, rotas, objetos e por elementos intangíveis como as memórias, narrativas, documentos escritos e tradição oral, rituais, festivais, sentimento de sagrado e de adoração, conhecimento tradicional, valores, texturas, cores, odores e outros, ou seja, os elementos físicos e espirituais que dão significado, emoção, sentimento e mistério ao lugar. O bem material, tangível, não é mais considerado de forma destacada do espírito do lugar, seu componente intangível. Nada há de adverso entre eles, ambos se interagem e se edificam de forma mútua e recíproca.

A capacidade de percepção do espírito de uma paisagem é uma experiência altamente enriquecedora para aquele que a contempla. No entanto, em conseqüência de problemas do mundo moderno como mudanças climáticas, turismo, conflitos armados e desenvolvimento urbano desordenado provocarem transformações e ruptura nas sociedades e nas paisagens que as identificam, torna-se necessário defender e preservar, conjuntamente com os bens culturais, o espírito que os anima.

A apreensão da paisagem varia segundo indivíduos, grupos ou toda uma sociedade. A forma como os habitantes de uma região a percebem fundamenta-se em experiências locais, familiares ou pessoais. Um rio oculta o segredo daqueles que afogou, aqueles que conheceram ou cuja história aprenderam de seus antepassados. $\mathrm{O}$ visitante advindo de outras paragens, mesmo não dispondo dessas informações, poderá intuir, poderá pressentir a sutil presença de reminiscências de possíveis episódios ocorridos naquela paisagem. O que perceberá em um dia sombrio irá diferir do que sentirá em um dia de sol.

Pessoas mais sensíveis poderão estremecer diante das corredeiras de um rio, da entrada de uma gruta, de uma grande montanha, enquanto outras permanecerão inteiramente indiferentes. $\mathrm{O}$ espírito dos lugares pode exercer uma influência benigna ou maligna, sobretudo quando se trata de um local sagrado. Com freqüência os locais que representam expressões de profundo sentimento de sagrado são invioláveis. Tocá-los é uma profanação, um tabu.

Existem recursos práticos para descobrir as manifestações do espírito dos lugares e de certas condições físicas invisíveis. Para a radiestesia, a existência de forças que se revelam sob a forma de radiação na natureza é um fato indiscutível. Quando o corpo humano não pode perceber muitas formas de energia emitidas pelo solo ou pelo subsolo, dispositivos como uma forquilha ou um pêndulo permitem localizar as fontes de radiação terrestres, sobretudo originadas de veios de água, do lençol aqüífero ou de falhas do terreno, permitindo assim diagnosticar certas condições de um sítio ou paisagem.

Muitas formas de apreensão do espírito da paisagem são coletivas. Ao experimentar um sentimento indizível de arrebatamento diante de um fenômeno da natureza manifestado em uma determinada paisagem, uma emoção que só poderia advir de uma manifestação divina, os antigos gregos escolhiam esse sítio para nele erguer um templo. Conforme a presença daquilo que apreendiam, o templo era consagrado a um deus. A cada divindade correspondia um diferente sítio, nos quais o homem helênico dedicava-se a orações, fazia oferendas e promovia sacrifícios banhados a sangue, após o que eram imolados e queimados animais. A fumaça de seus corpos, ao subir ao céu, era o alimento desejado pelos deuses.

O conceito de espírito dos lugares definido pela Carta do Espírito dos Lugares pode parecer uma volta nostálgica aos movimentos românticos que tentaram restituir à natureza seu aspecto encantado e que hoje se acha destruído pela visão desumana e pragmática da economia moderna. No entanto, a expressão antecede de muito o Romantismo, pois corresponde à idéia latina de genius loci, os gênios dos lugares, seres existentes ou fantásticos que guardavam e protegiam os lugares sagrados ou profanos de muitos povos.

A cosmovisão erudita dos tempos modernos descarta a existência de tais seres. O crédito dessas entidades sobrevive, contudo, em hipóteses vulgares como, por exemplo, em crenças orientais como o Feng Shui para o qual os aspectos imateriais de um lugar são mais importantes que os materiais. Estudos pseudocientíficos consideram pressuposições como as que certos alinhamentos megalíticos pré-históricos constituem formas terrestres de energia resultantes da interseção de linhas como ocorre nos misteriosos sítios arqueológicos megalíticos de Carnac, na França e Stonhenge, Glastonbury Newgrange e Avebury na Inglaterra.

A cada formação do mundo natural como rios, mares lagos, desertos, montanhas, cavernas, corresponde uma manifestação do mundo imaterial, quando não espiritual. Os rios separam as terras e seu curso pode ser uma corrente da vida ou da morte. A insondável imensidão dos lagos, mares e oceanos inspiram ao homem os mais profundos estados de respeito e adoração. Conforme estejam serenos ou turbulentos, predispõem á contemplação ou exaltam a imaginação.

Há paisagens terríveis cuja contemplação é aflitiva. Somente a graça divina pode salvar quem se desespera com o desolamento e a aridez de um deserto, local afastado de Deus e dos homens, propício às mais terríveis formas de tentações demoníacas ou, paradoxalmente, a revelações divinas. As montanhas, sólidos elementos de ligação entre o céu e a terra, por sua proximidade com os céus e por transmitirem impressão de perenidade, de imutabilidade e por despertarem sentimentos de adoração celestial, são procuradas por místicos e religiosos. Nas cavernas, pontos de penetração para o mundo das sombras e das trevas, habitam entidades do medo, do pânico e do terror.

Há quem acredite que às fendas geológicas do planeta correspondam locais de forte energia mística e religiosa com forte influência sobre a humanidade. Dentre elas citese um complexo de fendas criado pela separação das placas 
tectônicas que correspondem à região do Mar Morto, um ponto de concentração de energia telúrica que esclareceria porque, em Jerusalém, haveria uma forte irradiação de forças, explicando a razão pela qual a cidade é sagrada para cristãos, judeus e islamitas, abrigando o Santo Sepulcro, o Muro das Lamentações e a Cúpula da Rocha. Também Machu Pichu, de onde se descortina o vale sagrado dos Incas, está situado sobre duas falhas paralelas situadas entre dois picos.

$\mathrm{Na}$ América do Sul, muitas culturas se utilizam do traçado de linhas retas em suas intervenções na paisagem. Ao longo de vastas extensões de terras, como ocorre com os gigantescos e até hoje misteriosos geoglifos da cultura Nazca no deserto peruano, foram traçados gigantescos grafismos em forma de linhas e outras representações geométricas, ou de estilizações de plantas, animais e até de seres humanos. Os recentes desmatamentos da Amazônia revelaram a existência, sob a floresta, de gigantescos grafismos, em forma de figuras geométricas, os geoglifos do Acre.

Há locais que, para nos provocar sensações, dispensam a existência material, bastando sua existência imaterial, mitológica ou fantástica. Dentre essas paragens descritas por romancistas e poetas ou retratadas por pintores, citem-se locais imaginários como Shangri-La, domínio terral ou paraíso celestial, o mais alto mosteiro do mundo, situado na mais bela montanha do mundo e isolado de todas as formas de corrupção terrena; as legendárias terras de $\mathrm{Oz}$ ou de Nárnia; continentes inteiros, sejam submersos há quase doze mil anos como Atlântida, descrita pela primeira vez por Platão, sejam mundos subterrâneos como Pellucidar, possuidor de seu próprio sol e cuja floresta dos mortos jaz em perpétuo crepúsculo; o lendário Eldorado, cidade cujas construções seriam todas feitas em ouro maciço, com indescritíveis tesouros, na América Central ou do Sul, cujo imperador se espojava no ouro em pó para dar à pele a cor dourada.

\section{BIBLIOGRAFIA CONSULTADA}

ARTOLA, J. P. O Sagrado. O Correio da UNESCO, ano 19, n. 1.

CHEVAliER, J.; GHEERBRANT, A. Dicionário de Símbolos. 2 ed. Editora José Olimpo, 1990.

DESCHAMPS, Sophie-Lequime. As Paragens do Indizível. O Correio da UNESCO, ano 19, n. 1.

GOLVIN, Jean-Claude. A Morada da Eternidade. O Correio da UNESCO, ano 19, n. 1.

MANGUEL, A.; GUADALUPI, G. The Dictionary of Imaginary Places. Bloomsbury, 1999.

WESTWOOD, J. Lugares Misteriosos. Ediciones del Prado, V. I. 1995.

WESTWOOD, J. Lugares Misteriosos. Ediciones del Prado, v. II. 1995. 